\title{
Anal Fistül Tedavisinde Minimal İnvaziv Seçenek; Fistül Traktının Lazer Ablasyonu, İlk Deneyimlerimiz, Retrospektif Çalışma
}

\author{
Minimally Invasive Option in Anal Fistula Treatment; Laser Ablation of the Fistula Tract, Our \\ First Experiences, Retrospective Study
}

Yasin DURAN

Namık Kemal Üniversitesi, Tıp Fakültesi, Genel Cerrahi Anabilim Dalı, Tekirdağ, Türkiye

\section{Özet}

Amaç: Anal fistül cerrahi tedavisinde birçok yöntem uygulanmaktadır ancak yüksek nüks ve inkontinans gelişme riski nedeni ile yeni arayışlar devam etmektedir. Yeni bir teknik olan fistül traktını lazer ile ablasyon (LAFT) anal fistül tedavisinde sfinkter koruyucu bir tedavi seçeneği olarak kullanılmaya başlamıştır. LAFT bir diyot lazer kaynağına bağlı radyal fiber prob tarafından $360^{\circ}$ dairesel olarak yayılan lazer enerjisi kullanılarak fistül traktının kapatılması esasına dayanır. Biz bu çalışmamızda LAFT uyguladığımız hastaların kısa dönem sonuçlarını paylaşmayı amaçladık.

Gereç ve Yöntemler: Eylül 2017-Ocak 2020 arasında 33 hastaya aynı cerrah tarafından LAFT tekniği uygulandı. Fiber lazer fistül traktı içerisine yerleş̧irildi ve $1470 \mathrm{~nm}$ dalga boyunda ve 13 watt gücünde radyal fiber lazer, fistül traktına $360^{\circ}$ dairesel olarak uygulanarak tüm fistül traktı kapatıldı.

Bulgular: Ortalama takip süresi 29.96 ay (18-45 ay) idi. Hastaların 11 (\%33.33)'inde nüks görüldü. Ortalama nüks görülme süresi $1.75+/-0.52$ ay olarak tespit edildi. Hiç bir hastada fekal ve gaz inkontinansı görülmedi.

Sonuç: Anal sfikter kaslarını minimal etkilemesinden dolayı LAFT tekniğinin, fekal ve gaz inkontinans komplikasyonu az görülmektedir. Bu yüzden LAFT tekniğinin kısa sürede iyi fonksiyonel sonuçlarından dolayı anal fistüllerin tedavisinde öneriyoruz. Etkinliğinin ortaya konması için uzun süreli ve geniş kapsamlı klinik çalışmalara ihtiyaç vardır.

Anahtar Kelimeler: Anal fistül, LAFT, Nüks, İnkontinan

\section{Abstract}

Objectives: Many methods are used in the surgical treatment of anal fistulas, however new studies are still conducted due to the high risk of recurrence and incontinence. Laser ablation of the fistula tract (LAFT), a new technique, has started to be used as a sphincter-sparing treatment option in the treatment of anal fistulas. LAFT is based on closing the fistula tract by using $360^{\circ}$ circularly radiated laser energy by a radial fiber probe connected to a diode laser source. In this study, we aimed to share the short-term results of the patients to whom we applied LAFT.

Materials and Methods: LAFT technique was applied to 33 patients by the same surgeon between September 2017-January 2020. The fiber laser probe was inserted into the fistula tract. The entire fistula tract was closed by applying a radial fiber laser with a wave length of $1470 \mathrm{~nm}$ and a power of 13 watt $360^{\circ}$ circularly to the fistula tract.

Results: Average follow-up period was 29.97 months (18-45 months). 11(33.33\%) of the patients had recurrence. The mean recurrence time was evaluated as $1.75+/-0.52$ months. Faecal and gas incontinence are not observed in any patient.

Conclusion: Complications of fecal and gas incontinence are rarely observed, since the LAFT technique has minimal effect on the anal sphincter muscles. We recommend the LAFT technique in the treatment of anal fistulas, as it has good functional results in a short time. Long-term and comprehensive clinical studies are needed to demonstrate its efficacy.

Keywords: Anal fistula, LAFT, Recurrence, Incontinence

Yazışma Adresi: Yasin DURAN, Namık Kemal Üniversitesi, Tıp Fakültesi, Genel Cerrahi Anabilim Dalı, Tekirdağ, Türkiye Telefon: +90 50781122 94, Mail: yduran@nku.edu.tr

ORCID No (Surasıyla): 0000-0003-2290-7255

Geliş Tarihi: 06.04.2021

Kabul Tarihi: 23.08.2021

DOI: $10.17517 /$ ksutfd. 948192 


\section{GÍRİş}

Anal fistül, düşük yaşam kalitesi ile ilişkili, anal bölgede ağrı, iltihabi akıntı, apse gibi belirtilerle kendisini gösteren yaygın bir anorektal hastalıktır $(1,2)$. Anal fistül anorektal bir hastalık olup \%90'dan fazlası kriptoglandüler kökenlidir ve anorektal apselerden sonra ortaya çıkmaktadır (3). Park sinıflamasına göre fistüller intersfinkterik, transsfinkterik, suprasfinkterik ve ekstrasfinkterik olarak dört ana gruba ayrılmıştır (4). Anal fistül tedavisinde cerrahi tedaviler ve teknikteki birçok gelişmeye rağmen kesin cerrahiyi takiben vakaların yaklaşık olarak \% 30'unda başarısız sonuçlar ortaya çıkar, anal fistülün cerrahi tedavisi fekal kontinansı etkileyebilir ve bu da yaşam kalitesini bozabilir $(1,2,5,6)$. Fistüloto$\mathrm{mi}$, anal fistüllerin tedavisinde altın standarttır, iyileşme oranı \%90'ın üzerindedir (7-9). Ancak fistülotomiyle tedavi edilen hastalar postoperatif anal sfinkter fonksiyon bozukluğu gelişme riski altındadır; özellikle kadınlar, kompleks fistüller, nüksetmiş anal fistül hastaları veya önceki anorektal cerrahi geçiren hastalarda risk artmaktadır $(9,10)$.

Cerrahi başarısızlığa bağlı anal fistül nüksünün ana nedenleri gözden kaçan ve tedavi edilmeyen bir iç açıklık, fistül epitel kalıntıları, geride bırakılmış birincil fistül traktı ve gözden kaçan ikincil fistül traktlarıdır $(5,6,11,12)$. Bildirilen genel inkontinans oranları fistül türüne ve kullanılan cerrahi tedavi şekline bağlı olarak \%40’a kadar değişir (13). Son zamanlarda, cerrahiyi daha az invaziv hale getirmek ve postoperatif fekal inkontinans olasılığını azaltmak amacıyla anal fistül tedavisinde sfinkter koruyucu tedavi yöntemleri kullanılmaya başlanmıştır (14). Sfinkter koruyucu prosedürler arasında intersfinkterik fistül traktının ligasyonu (LIFT), video yardımlı anal fistül tedavisi (VAAFT), anal fistül tıkacı ve çeşitli biyomateryallerin kullanımı bulunmaktadır $(2,15)$. Yeni bir teknik olan fistül lazer kapatma (LAFT), anal fistül tedavisi için sfinkter koruyucu bir prosedürüdür. Fistül lazer kapatma bir diyot lazere bağlı bir radyal fiber tarafından yayılan lazer enerjisi kullanılarak, radyal fiber etrafindaki dokunun büzülerek fistül traktının kapanmasını sağlar $(6,16)$.

$\mathrm{Bu}$ retrospektif çalışmanın amacı anal fistülü olan hastalarda lazer prosedürünün nüks, inkontinans ve diğer komplikasyonlar açısından güvenliğini ve etkinliğini değerlendirmektir.

\section{GEREÇ VE YÖNTEMLER}

Tekirdağ Namık Kemal Üniversitesi hastanesi Genel Cerrahi kliniğinde Eylül 2017 -Ocak 2020 arasında 33 hastaya aynı cerrah tarafından LAFT tekniği uygulandı. Çalışma Tekirdağ Namık Kemal Üniversitesi Girişimsel olmayan klinik araştırmalar etik kurulunun 27.05.2021 tarih ve 2021.147.05.20 sayılı etik kurul kararı ile tarafından onaylandi. Bu çalışma Helsinki Deklerasyonu prensiplerine uygun olarak yapılmıştır. LAFT prosedürüne giren tüm hastalardan bilgilendirilmiş onam formu alındı. Çalışmamızda; protokole bağlı kalınarak Dünya Tıp Birliği Helsinki Bildirgesinin etik kurallarına uyulmuştur. Hastaların çalışmaya dahil edilme kriterleri, transsfinkterik fitül, ekstrasfinkterik fistül, sup- rasfinkterik fistül, intersfinkterik fistül olması, inkontinans olmaması olarak belirlendi. Hariç tutulma kriterleri olarakta malignite ile ilişkili fistüller, submukozal fistüller, perianal fistül beraberinde apse olması, inkontinans olması, sekonder fistül traktlarının olması olarak belirlendi. Temel hasta demografik verileri (yaş, cinsiyet) ile birlikte fistül tipi ve önceki cerrahi tedavilere ilişsin bilgiler toplanmıştır. Ayrıca hastalara preoperatif inkontinans olup olmadığı sorguland. Hiçbir hastada preoperatif inkontinans yoktu, sfinkter tonusu fizik muayenede normal olarak değerlendirildi. Hastaların 20’si erkek (\%60.6), 13’ü kadın (\%39.3) ortalama yaş 43.151 yıl (22-67 yaş) (Tablo 1). Hastalar ameliyat öncesi fizik muayene, rektosigmoidoskopi ve pelvik manyetik rezonans görüntüleme (MRI) çekilerek değerlendirildi. Fistüllerin 18'i intersfinkterik fistül, 9'u transsfinkterik, 5'i suprasfinkterik, 1'i ekstrasfinkterik fistül olarak değerlendirildi. Hastaların 18'ine daha önceden peri anal apse drenajı uygulanmıştır (Tablo 2).

\begin{tabular}{|c|c|}
\hline Tablo 1. Hastaların Demografik Verileri \\
\hline Özellikler & Hasta $(\mathbf{n}(\%))$ \\
\hline Yaş & $22-67(43,15+/-2,15)$ \\
\hline Cinsiyet (Erkek/Kadın) & $20(\% 60,60) / 13(\% 39,39)$ \\
\hline
\end{tabular}

Tablo 2. Hastaların ameliyat öncesi özellikleri

\begin{tabular}{|l|c|}
\hline Özellik & n(adet) \\
\hline İntersfinkterik fistül & 18 \\
\hline Transsfinkterik fistül & 9 \\
\hline Suprasfinkterik fistül & 5 \\
\hline Ekstrasfinkterik fistül & 1 \\
\hline İnkontinans & 0 \\
\hline Preoperatif abse drenajı & 18 \\
\hline
\end{tabular}

\section{Cerrahi Teknik}

Hastalara ameliyat öncesi rutin anestezi muayenesi yapıldı. Tüm hastalara preoperatif lavman ile barsak temizliği uyguland. Operasyondan 2 saat önce profilaktik 1 gr Cefazolin Na IV ve Metranidazol $500 \mathrm{mg}$ tablet uyguland. Hastalar spinal anestezi altında ameliyata alındı. Spinal anesteziyi takiben hastalar litotomi pozisyonuna alınıp boyandıktan sonra örtüldü. Sonra operasyona başlandı. İşlem için önce dış fistül ağzından metilen mavisi verilerek iç fistül ağzı ortaya kondu. Fistül traktı bir firça ile mekanik olarak kürete edildi ve serum fizyolojik ile yıkandı. 30 hastada fistül traktı bulunarak, fırça ile mekanik olarak kürete edildi, ancak 3 (2 suprasfinkterik, 1 ekstrasfinkterik) hastada iç fistül ağzına ulaşılamadı. İç fistül ağzına ulaşılamayan bu 3 hasta dışında kalan 30 hastada iç fistül ağzı primer sütür ile kapatıldı. Fiber lazer fistül traktı içerisine yerleştirildi ve $1470 \mathrm{~nm}$ dalga boyunda ve 13 watt gücünde radyal fiber lazer, fistül traktına $360^{\circ}$ dairesel olarak uygulandı. Prob adım adım geri çekilerek tüm fistül traktı boyunca radyal lazer uygulanarak epitel 
dokusu yok edilerek tüm fistül traktı kapatıldı. Diyot lazer enerjisi, su ve kan ile etkileşime girerek radyal yayan lazer lifi etrafındaki fistül yolunun pıhtılaşmasına ve büzüşerek kapanmasına yol açar.

\section{İstatistiksel Analiz}

İstatistik değerlendirme; bilgisayar ortamında, Statistical Package for the Social Sciences (SPSS 25.0 version) programında yapıldı. Sonuçlarımız ortalama \pm standart sapma şeklinde verildi. Hastalar değerlendirildikten sonra değişkenler ortalama, standart sapma, frekans ve yüzde ile ifade edilmiştir. $\mathrm{P}<0.05$ değeri istatiksel olarak anlamlı kabul edildi

\section{SONUÇLAR}

Hastaların yapılan muayenesinde $\% 54.55$ 'i intersfinkterik fistül, \%27.27'si transsfinkterik fistül, \%15.15'i suprasfinkterik fistül, \%3.03’ü ekstrasfinkterik fistül olduğu görülmüştür. Ortalama ameliyat süresi 17.0303+/-0.83766 dakika olarak tespit edildi. Operasyon sonrasinda hastalar servise alındi. Postoperatif düşük düzeyde rektal ağrı oldu, gereklilik halinde analjezik uygulandı. Hastanede kalış süresi ortalama bir gün oldu. Hastalar taburcu edilirken 1000 mg Sefaleksin tablet verildi. İlk bir yıl boyunca hastalar ayda, daha sonra 6 ayda bir kontrole çağırılarak muayenesi yapıldı. Hastalar ortalama 29.9697 ay (18-45ay) takip edildi. Takiplerde hastalarda nüks gelişimi, apse gelişimi ve inkontinans değerlendirildi (Tablo 3). Hastaların muayenesinde dış fistül ağzı açıklığının varlığı, dış fistül ağzından iltihabi akıntı olması nüks olarak değerlendirildi. 11 hastada (\%33) nüks görüldü, ortalama nüks süresi $1.75+/-0.52$ ay olarak tespit edildi. Nüks etmiş olan hastaların ameliyat öncesi fistül tipi incelendiğinde 1 tanesi ekstrasfinkterik fistül, 3 tanesi suprasfinkterik fistül, 3 tanesi transsfinkterik fistül, 4 tanesi ise intersfinkterik fistül olan hastalardı. Nükslerin yüksek fistüllerde daha fazla oranda görüldüğü ve literatür ile uyumlu olduğu görülmüştür (12). İç fistül ağzı bulunamayıp sutüre edilmeyerek kapatılamamış olan 3 vakanın 2'si (\%66.6) nüks etmiş olduğu görüldü. İç fistül ağzı sütüre edilerek kapatılan 30 hastanın 8’i (\%26.6) nüks ettiği görüldü, bu nedenle iç fistül ağzının kapatılmasının nüks oranını azalmasında etkili olabileceği yönünde değerlendirilmiştir. Hastalarda gaz ve/veya gaita inkontinansı olup olmadığı sorgulanarak değerlendirildi ayrıca rektal tuşe ile sfinkter tonusu değerlendirildi. Postoperatif bir (\%3.03) hastada apse oluştuğu görüldü, apse gelişen hastaya tedavi için $500 \mathrm{mg}$ Sodyum Fusidat verildi. Abse oluşan hastada daha sonra nüks gelişti. Hiçbir hastada gaz ya da gaita inkontinansı görülmedi. Postoperatif gelişen komplikasyonlar değerlendirildi (Tablo 3). Hastalarda preoperatif

Tablo 3. Postoperatif komplikasyonlar

\begin{tabular}{|l|c|}
\hline Komplikasyon & $\mathbf{n}(\mathbf{a d e t})$ \\
\hline İnkontinans & 0 \\
\hline Nüks & 11 \\
\hline Postoperatif Abse & 1 \\
\hline
\end{tabular}

ve postoperatif kontinans durumu Cleveland klinik fekal inkontinans skoru tablosuna göre değerlendirildi. Preoperatif inkontinans hiçbir hastada yoktu. Postoperatif inkontinans hiçbir hastada gelişmedi.

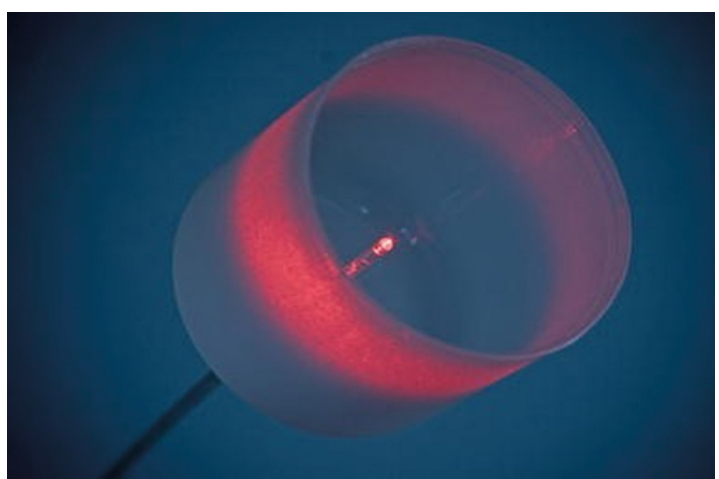

Resim 1. Radyal yayan lazer probu (-A Wilhelm. A new technique for sphincter-preserving anal fistula repair using a novel radial emitting laser probe. Tech Coloproctol. 2011 Dec;15(4):445-9. doi: 10.1007/s10151-011-0726-0. )

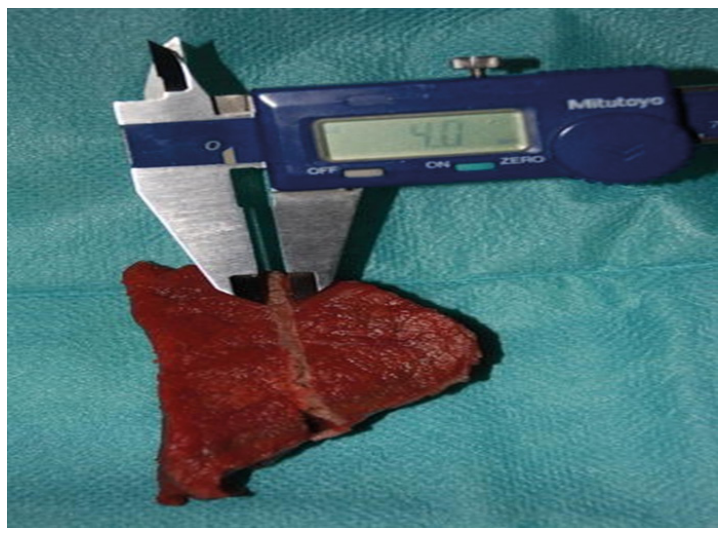

Resim 2. Ex vivo çalışmalar, kas dokusu içindeki1, $470 \mathrm{~nm}$ diyot lazerin sınırlı penetrasyon derinliğini göstermektedir. (A Wilhelm. A new technique for sphincter-preserving anal fistula repair using a novel radial emitting laser probe. Tech Coloproctol. 2011 Dec;15(4):445-9. doi: 10.1007/s10151011-0726-0.)

\section{TARTIŞMA}

Anal fistül hastalığının tedavisi cerrahidir (13). Fistül cerrahisindeki tedavinin amac1, inkontinans'a neden olmadan süpüratif süreci kalıcı olarak ortadan kaldırmaktır (13). Anal fistül cerrahisinin altın standardı fistülotomi işlemi olarak kabul edilmektedir $(13,14,17)$. Ancak bu tedavi daha çok intersfinkterik fistüller ve alçak transsfinkterik fistüllerin tedavisinde iyi sonuç vermektedir (12). Fistül seviyesi yükseldiğinde $\% 2-20$ oranında gaz ve gaita inkontinansı ve fistül nüksü gibi istenmeyen sonuçlar ortaya çıkabilmektedir $(13,14,17,18)$. Anal fistül tedavisinde nüks ve anal inkontinans ile yüksek transsfinkterik fistül, saptanmamış iç açıklık, at nalı uzantıları ve birden fazla fistül traktı olması ile anlamlı 
olarak ilişkili olduğu belirlenmiştir ve bu durum cerrahları başka tedavi arayışlarına yöneltmiştir $(9,10,13,19,20)$. Düşük transsfinkterik fistül için \%10.7'lik nüks oranı ile karşılaştırıldığında, anal fistül nüks oranları yüksek transsfinkterik yollar için sırasıyla \%37.8 ve at nalı uzantılı yollar için \%44.4 idi $(19,20)$. Suprasfinkterik fistüller en yüksek anal fistül nüks oranlarından birine sahiptir $(10,19,20)$ ve tespit edilmemiş bir iç açıklık anal fistül nüksünü \% 43 ila \%53 arasına yükseltir $(9,10,20)$. Burada amaç anal inkontinansı engellemek ve nüksü ortadan kaldırmaktır (13). Geniş kapsamlı bir çalışma olan Vial ve ark. yaptığı seton uygulaması yapılan çalışmaların irdelendiği sistematik derleme çalışmada 448 hastanın incelemesinde fekal inkontinans \%5.6-25.2 arasında değişmekte iken nüks oranı ise \%3-5 tespit edilmiş $(13,21)$. İnkontinans gelişimini engellemek için geliştirilen sfinkter koruyucu prosedürler arasında LIFT, VAAFT, anal fistül tıkacı ve çeşitli biyomateryallerin kullanımı gibi yöntemler bulunmaktadır $(2,15)$.

Son zamanlarda geliştirilen lazer probu kullanılarak sfinkter koruyucu, fistül epitelini yok ederek anal fistül onarımı gerçekleştiren bir yöntem kullanılmaktadır (6). Diyot lazere bağlı bir radyal fiber tarafindan yayılan lazer enerjisi1470 nm dalga boyu, 2-3 mm penetrasyon derinliği kadar etki eder ve homojen radyal yayılan lazer enerjisi, intralüminal olarak büzülme ve denatüre edici etki ile dokuda kontrollü bir iyileşme ile sonuçlanır $(5,13,16)$. (Resim 1)

$\mathrm{Bu}$ yeni lazer teknolojisi, Alman makamları ve Gida ve İlaç Dairesi (FDA) (Uygunluk Beyanı, Ceram Optic GmbH, Bonn, Almanya) tarafından endovenöz ve hemoroidal tedavi dahil olmak üzere çeşitli cerrahi ve endoskopik prosedürler için onaylanmıştır (6). Ex vivo çalışmalarda, kas ve karaciğer dokusunda sınırlı penetrasyon derinliğini doğrulanmış ve tedavi için uygun enerjiyi belirlenmiştir (6) (Resim 2).

Cerrahi travma çok düşüktür ve hipertermik etki minimal ve reversibl olarak kabul edilmektedir (16). LAFT tedavisi ile anal fistülün iyileşme oranları değişiklikler göstermektedir. 476 hastayı içeren 8 çalışmanın meta-analizinde, fistül traktı Lazer Ablasyonu sonrasında ortalama iyileşme oranı \% 63 ve postoperatif komplikasyon oranı $\% 8$ olarak bulunmuştur (22,23). Bununla birlikte, yayınlanmış serilerde başarı oranları, büyük yayılma için tek bir bariz neden olmaksızın \% 20-\%80 arasında önemli ölçüde değişiklik göstermektedir $(6,24,25)$. Bizim çalışmamızda LAFT tedavisi başarı oranı \%66.66 olarak tespit edilmiş olup, literatür ile uyumlu olarak değerlendirilmiştir. Bugüne kadar LAFT, ilerletme flepleri (IF), LIFT ve VAAFT gibi karmaşık fistüller için diğer iyi bilinen tekniklere karşı randomize klinik çalışmalarda değerlendirilmemiştir, sistematik incelemelerde, bu tekniklerde \%70 civarında başarı oranları gösterilmiştir $(26,27)$ ve LAFT ile benzer başarı oranına sahip olduğu görülmektedir. 2020 yılında 26 çalışmadan yapılan bir meta analizde LIFT'in ortalama başarı oranı $\% 76.5$, ortalama komplikasyon oranı $\% 13.6$, ortalama nüks $\% 9.6$, ortalama fekal inkontinans oranı \%0.6 idi (28). LIFT benzer başarı ve nüks oranlarına sahiptir ancak perinede ilave insizyon gerektirmektedir. VAAFT'den sonra ortalama başarı oranını \%76.01 ve ortalama komplikasyon oranını \%16.2 gösterdi (22). VAAFT benzer başarı oranına karşın komplikasyon oranı LAFT’a göre daha yüksek olduğu görülmektedir. Anal fistülün fistül tıkacı ile tedavisi \%50-60'lık bir başarı oranına ve \%10-20'lik bir komplikasyon oranına sahiptir $(22,29)$, bu oranlar ile anal fistül tıkacı tedavisinin başarı oranı daha düşük, komplikasyon oranının ise daha yüksek olduğu görülmektedir. Minimal invaziv bir teknik olan LAFT diğer sfinkter koruyucu tekniklerle karşılaştırıldığında inkontinans açısından daha düşük yan etki riskine sahiptir (23). Bizim çalışmamızda 33 hastanın hiç birisinde inkontinans görülmemiş olup, literatür ile uyumlu olarak değerlendirilmiştir.

Verilerin geriye dönük olarak incelenmesi, Crohn hastalığına bağlı fistül olmaması, at nalı fistüllerde uygulanmamış olması ve vaka sayısının az olması bu çalışmada ana kısıtlayıc1 faktörlerdir. LAFT tekniğinde uygulanan lazer enerjisinin fistül yolunun ötesinde $2-3 \mathrm{~mm}$ 'lik bir radyal penetrasyon derinliği ile fistülün lümeniyle sınırlı olması ve bu nedenle inkontinans riskinin çok düşük olması, iç fistül açıklığının flep ile kapatılmayı gerektirmemesi, prosedürün uygulama süresinin kısa olması, öğrenmenin kolay olması, postoperatif ağrının çok düşük olması, fistülotomi gibi açık yara olmadiğından uzun süre pansuman gerektirmemesi, günlük hayat kısa sürede dönülebilmesi çalışmanın avantajları olarak değerlendirilebilir. Prosedürün pahalı olması, nüks oranının fistülotomi kadar düşük olmaması dezavantajlar olarak değerlendirilebilir.

Mei ve ark. tarafından yapılan bir meta-analizde, fistül özellikleri ile artmış fistül nüksü riski arasında bir ilişki bulundu (20). Daha düşük iyileşme oranları ile yüksek transsfinkterik fistüller, tespit edilmeyen bir iç açıklık, at nalı fistül varlığı, çoklu fistül yolları ve önceki anal cerrahi gibi fistül özellikleri arasında bir korelasyon bulunmuştur (20). Suprasfinkterik, ekstrasfinkterik, yüksek transsfinkterik ve komplike fistüllerde fistül traktının tamamen bulunamaması ve iç açıklığın her zaman bulunamaması ve bu nedenle iç açıklığın kapatılamaması prosedürün uygulanmasını zorlaştırmakta ve nüks riskini artırabileceği tespit edilmiştir $(10,20,30)$.

Sonuç olarak, LAFT prosedürünün, karmaşı anal fistüllerin cerrahi tedavisi sonrası ortaya çıkan yüksek inkontinans riskine karşı sfinkter koruyucu tedavi olarak etkili olduğunu göstermiştir $(2,11,16,22,23)$. Anal fistüllerin yönetimindeki rolünü daha iyi tanımlamak için LAFT prosedürünü diğer sfinkter koruyucu tekniklerle karşılaştıran prospektif randomize kontrollü uzun süreli ve geniş kapsamlı klinik çalışmalara ihtiyaç vardır.

\section{KAYNAKLAR}

1. Owen HA, Buchanan GN, Schizas A, Cohen R, Williams AB. Quality of life with anal fistula. Ann R Coll Surg Engl. 2016;98(5):334-338. doi:10.1308/rcsann.2016.0136

2. Wolicki A, Jäger P, Deska T, Senkal M. Sphincter-saving therapy for fistula-in-ano: long-term follow-up after Fi$\mathrm{LaC}^{\oplus}$. Techniques in Coloproctology. 2021;25(2):177-184 doi:10.1007/s10151-020-02332-4 
3. Nelson R. Anorectal abscess fistula: what do we know? Surg Clin North Am 2002;82(6):1139-1151. doi:10.1016/ s0039-6109(02)00063-4

4. Parks AG, Gordon PH, Hardcastle JD. A classification of fistula-in-ano. Br J Surg 1976;63(1):1-12.

5. Litza EM, van Wijk JJ, Gosselink MP, Doornebosch P, Zommerman DDE, Schouten WR. Seton drainage prior to transanal advancement flap repair: useful or not? Int J Colorectal Dis. 2010;1499-1502. doi:10.1007/s00384010-0993-7

6. Wilhelm A. A new technique for sphincter-preserving anal fistula repair using a novel radial emitting laser probe. Tech Coloproctol. 2011;15(4):445-9. doi:10.1007/ s10151-011-0726-0.

7. Hall JF, Bordeianou L, Hyman N, Read T, Bartus C, Schoetz D, et.al. Outcomes after operations for anal fistula: results of a prospective, multicenter, regional study. Dis Colon Rectum 2014;57(11):1304-1308. doi:10.1097/ DCR.0000000000000216.

8. Abramowitz L, Soudan D, Souffran M, Bouchard D, Castinel A, Suduca JM, et.al. The outcome of fistulotomy for anal fistula at 1 year: a prospective multicentre French study. Colorectal Dis 2016;18(3):279-285. doi: 10.1111/ codi. 13121

9. Garcia-Aguilar J, Belmonte C, Wong WD, Goldberg SM, Madoff RD. Anal fistula surgery. Factors associated with recurrence and incontinence. Dis Colon Rectum 1996;39(7):723-729. doi:10.1007/BF02054434

10. Jordán J, Roig JV, García-Armengol J, García-Granero E, Solana A, Lledó S. Risk factors for recurrence and incontinence after anal fistula surgery. Colorectal Dis 2010;12(3):254-260. doi:10.1111/j.14631318.2009.01806.x

11. Lunnis PJ, Sheffield JP, Talbot IC, Thomson JP, Phillips RKS. Persistence of idiopathic anal fistula may be related to epithelialisation. Br J Surg. 1995;82(1):32-33. doi: 10.1002/bjs. 1800820112

12. Sygut A, Mic M, Trzcinski R, Dziki A. How the location of the internal opening of anal fistulas affect the treatment results of primary trans-sphincteric fistulas. Langenbecks Arch Surg. 2010;395(8):1055-1060. doi:10.1007/s00423009-0562-0

13. Dönmez T, Hatipoğlu E. Closure of Fistula Tract with FiLaC $^{\text {mx }}$ Laser as a Sphincter-Preserving Method in Anal Fistula Treatment. Turk J Colorectal Dis 2017;27(4):142147. doi:10.4274/tjcd.06025

14. Limura E, Giordano P. Modern management of anal fistula. World J Gastroenterol. 2015;21(1):12-20. doi:10.3748/ wjg.v21.i1.12

15. Wilhelm A, Fiebig A, Krawczak M. Five years of experience with the FiLaC ${ }^{\mathrm{m}}$ laser for fistula-in-ano management: long-term follow-up from a single institution. Techniques in Coloproctology. 2017;21(4):269-276. doi:10.1007/ s10151-017-1599-7.

16. Giamundo P, Geraci M, Tibaldi L, Valente M. Closure of fistula-in-ano with laser--FiLaC ${ }^{\mathrm{Tm}}$ : an effective novel sphincter-saving procedure for complex disease. Colorectal Dis. 2014;16(2):110-5. doi: 10.1111/codi.12440.

17. Rizzo JA, Naig AL, Johnson EK. Anorectal abscess and fistula-in-ano: evidence-based management. Surg Clin N Am. 2010;90(1):45-68. doi: 10.1016/j.suc.2009.10.001
18. Taviloğlu K. Anal Fistül. Taviloğlu K. Kolorektal Hastalıklar ve Proktoloji.1. Baskı.İstanbul, Cinius Yayınları 2016;313-322.

19. MA Abbas, CH Jackson, PI Haigh. Predictors of outcome for anal fistula surgery. Arch. Surg. 2011;146(9):10111016

20. Mei Z, Wang Q, Zhang Y, Liu P,Ge M, Du P et. al. Risk factors for recurrence after anal fistula surgery: a meta-analysis. Int J Surg. 2019;69:153-164. doi:10.1016/j. ijsu.2019.08.003

21. Vial M, Parés D, Pera M, Grande L. Faecal incontinence after seton treatment for anal fistulae with and without surgical division of internal anal sphincter: a systematic review. Colorectal Dis 2010;12(3):172-178

22. Frountzas M, Stergios K, Nikolaou C, Bellos I, Schizas D, Linardoutsos D, et.al. Could FiLaCTM be effective in the treatment of anal fistulas? A systematic review of observational studies and proportional meta-analysis. Color Dis. 2020;22:1874-1884. doi:10.1111/codi.15148

23. Carstensen AN, Perregaard H, Hagen KB, Krarup PM. Fistula Laser Closure (FiLaC ${ }^{\mathrm{rm}}$ ) for fistula-in-ano-yet another technique with $50 \%$ healing rates? Int J Colorectal Dis. 2021;1-7. doi:10.1007/s00384-021-03932-8.

24. Stijns J, Van Loon YT, Clermonts SHEM, Göttgens KW, Wasowicz DK, Zimmerman DDE. Implementation of laser ablation of fistula tract (LAFT) for perianal fistulas: do the results warrant continued application of this technique? Tech Coloproctol. 2019;23(12): 1127-1132. https://doi.org/10.1007/s10151-019-02112-9

25. Oztürk E, Gülcü B. Laser ablation of fistula tract: a sphincter-preserving method for treating fistula-in-ano. Dis Colon Rectum. 2014;57(3):360-364. doi:10.1097/ DCR.0000000000000067

26. Stellingwerf ME, Van Praag EM, Tozer PJ, Bemelman WA, Buskens CJ. Systematic review and meta-analysis of endorectal advancement flap and ligation of the intersphincteric fistula tract for cryptoglandular and Crohn's high perianal fistulas. BJS Open. 2019;3(3): 231-241. doi:10.1002/bjs5.50129

27. Garg P, Singh P. Video-assisted anal fistula treatment (VAAFT) in cryptoglandular fistula-in-ano: a systematic review and proportional meta-analysis. Int J Sur. 2017; 46:85-91. doi:10.1016/j.ijsu.2017.08.582

28. Sameh HE, Sualeh M.K , Adeyinka A , Oyintonbra K. Ligation of intersphincteric fistula tract (LIFT) in treatment of anal fistula: An updated systematic review, meta-analysis, and meta-regression of the predictors of failure. Surgery. 2020;167(2):484-492. doi: 10.1016/j. surg.2019.09.012

29. Köckerling F, Alam NN, Narang SK, Daniels IR, Smart NJ. Treatment of Fistula-In-Ano with Fistula Plug - a Review Under Special Consideration of the Technique. Front Surg. 2015;2:55. doi:10.3389/fsurg.2015.00055.

30. Malakorn S, Sammour T, Khomvilai S, Chowchankit I, Gunarasa S, Kanjanasilp P, et. al. Ligation of Intersphincteric Fistula Tract for Fistula in Ano: Lessons Learned From a Decade of Experience. Dis Colon Rectum 2017;60(10):1065-1070. doi:10.1097/ DCR.0000000000000880 